\title{
Pessoa na língua dos Gavião de Rondônia1
}

\author{
Person in the language of the Gavião of Rondônia
}

Denny Moore

Museu Paraense Emilio Goeldi (MPEG/MCTI)

Resumo: Na língua dos Gavião de Rondônia, todas as classes de radicais (nomes, verbos, adjetivos, auxiliares), com exceção dos radicais de verbos intransitivos, podem receber como marcadores de pessoa clíticos pessoais ou pronomes pessoais livres. Existem quatro classes de clíticos pessoais e cada radical simples pertence a uma destas. Os clíticos pronominais marcam o possuidor de um radical nominal, o objeto de um radical de verbo transitivo, o sujeito da oração de um auxiliar e o núcleo do sintagma nominal de adjetivo. Marcam também concordância com o sujeito de verbos intransitivos.

Palavras chaves: marcação de pessoa, Gavião de Rondônia, família linguística Mondé

Abstract: In the language of the Gavião of Rondônia, with the exception of intransitive verb stems, all the classes of stems (noun, verb, adjective, auxiliary) can be marked for person by means of either pronominal clitics or free personal pronouns. There are four classes of person clitics and each simple stem belongs to one of these four classes. The pronominal clitics mark the possessor of a noun stem, the object of a transitive verb stem, the subject of the clause of an auxiliary, and the nucleus of the noun phrase of an adjective stem, as well as cross-referencing subjects of intransitives.

Keywords: Person marking. Gavião of Rondônia. Mondé language Family

Introdução

A língua dos Gavião de Rondônia tem aproximadamente 550 falantes. Ela faz parte da família linguística Mondé, do tronco Tupi (Autor, 2006). A marcação de pessoa não se dá do mesmo jeito em todas as línguas da família: na língua dos Paiteer (Surui de Rondônia), por exemplo, marca-se a correferência em todas as pessoas, ao contrário da língua dos Gavião, em que a correferência é marcada apenas na terceira pessoa. Nes artigo, serão apresentados os paradigmas dos clíticos pronominais e, em seguida, o comportamento destes marcadores de pessoa com as diferentes classes de radicais de palavras. Deve-se observar que não há posposições como classe de palavra em Gavião. Estas formam uma subclasse dos verbos transitivos, com base em sua distribuição. Os tópicos deste trabalho são discutidos em maior detalhe em Autor (1984).

\footnotetext{
${ }^{1}$ Trabalho apresentado no Simpósio “A correlação entre a expressão da pessoa e outros fenômenos gramaticais em línguas indígenas", organizado pelo Núcleo de Tipologia Linguística (NTL), dentro da programação do IV CIELLA Congresso Internacional de Estudos Linguísticos e Literários na Amazônia. Belém-PA, 24 e 25 de abril de 2013 , Universidade Federal do Pará.
} 


\section{Paradigmas de clíticos pronominais}

Há quatro séries de clíticos pronominais que podem ser identificadas convenientemente pelas formas da segunda pessoa do singular: $e_{-}, e_{-}, e^{-e ́}-e^{e} e_{-}^{23}$. Os paradigmas são ilustrados abaixo, com nomes. A forma pós-nominal é uma forma (radical) livre que ocorre após um sintagma nominal. A terceira pessoa correferencial/cross-referencing é diferente das outras por sempre marcar concordância e não possuir um pronome livre correspondente.

(1) Quatro classes de clíticos pronominais

\begin{tabular}{lllll}
\hline Classe & $\boldsymbol{e}$ - & é- & é́- & éè- \\
\hline Glossa & mão & cheiro & esteira & irmã (de homem) \\
Forma básica & pábe & ka & ákápe & paàt \\
Pós-nominal & pábe & ka & ákápe & paàt \\
\hline $\mathbf{1 s}$ & bâbe & Q́-ga & oó-kápe & óò-baàt \\
$\mathbf{2 s}$ & ę-bábe & ę-ga & eé-kápe & éè-baàt \\
$\mathbf{3 s}$ & ci-pabe & ci-ka & saa-kápe & cii-paàt \\
\hline $\mathbf{3 c}$ & a-pabe & a-ka & aa-kápe & aa-paàt \\
$\mathbf{1 p i}$ & pa-bábe & pa-ga & paá-kápe & paa-paàt \\
$\mathbf{1 p e}$ & to-pábe & to-ka & tóó-kápe & tóò-paàt \\
$\mathbf{2 p}$ & me-pábe & me-ka & meé-kápe & mee-paàt \\
$\mathbf{3 p}$ & tá-pábe & tá-ka & táá-kápe & táa-paàt \\
\hline
\end{tabular}

Os radicais monossilábicos que começam por vogal têm uma oclusiva glotal e uma juntura aberta entre o radical e o clítico pronominal; por exemplo, e-'-ót 'comedor de você'. Radicais que se iniciam por vogal e têm mais de uma sílaba tomam clíticos longos, das classes eé- ou éè-, provavelmente por causa de um processo diacrônico de fusão vocálica, com reinterpretação da vogal prolongada como parte do clítico. Existem, contudo, também radicais iniciados por consoante que ocorrem com clíticos longos; por exemplo, ciisaá 'fígado dele'.

O tom da primeira sílaba da forma básica do radical condiciona parcialmente a classe do clítico pronominal, sugerindo que, historicamente, o tom inicial do radical era o oposto do tom do clítico. Os radicais que tomam clíticos das classes é- e éè- sempre têm sílabas iniciais com tom baixo. O tom da primeira sílaba da forma básica dos radicais que

${ }^{2}$ Transcrição: Os símbolos c e $j$ indicam africadas palatais, y o glide palatal, e $s$ e $z$ africadas dentais. A fricativa bilabial sonora é representada por $v$, e a oclusiva glotal por um apóstrofo. Vogais prolongadas são indicadas por sequências de duas vogais. O tom baixo não é marcado. O tom alto é marcado por um acento agudo, o tom ascendente por um circunflexo, e o tom alternante por um acento grave. Aspas indicam citações ou pensamentos em Gavião. A nasalização de vogais é marcada por um ogonek (cedilha sob a vogal).

${ }^{3}$ Abreviações: 1pi=primeira pessoa inclusiva, 1pe=primeira pessoa exclusiva, $2 \mathrm{~s}=$ segunda pessoa do singular, $2 \mathrm{p}=$ segunda pessoa do plural, $3 \mathrm{~s}=$ terceira pessoa do singular, $3 \mathrm{c}=$ terceira pessoa correferencial/cross-referencing, $3 p=$ terceira pessoa do plural, $P L=$ plural, $S G=$ singular, $A U X=$ auxiliar, $C O P=$ cópula, NMLZ=nominalização, TRANS=transitivização, OBJ=objeto, DIMIN=diminutivo, NOM=tipo funcional nominal 
tomam clíticos das classes e- e eé- é geralmente alto, com várias exceções: por exemplo, be 'caminho', ę-bé 'seu caminho'. A forma pós-nominal destes radicais sempre tem tom alto na sílaba inicial; por exemplo, do pé 'caminho da serra'.

O alomorfe ci- da terceira pessoa do singular e o clítico $a$ - 'correferencial/crossreferencing' geralmente abaixam o tom da primeira sílaba de radicais nominais que seguem, mas não têm este efeito nos radicais de outras classes de palavras. O clítico da terceira pessoa do singular tem três alomorfes nos radicais nominais, cuja ocorrência é em parte fonologicamente condicionada: ci-, saa/taa-, e $\varnothing$-. A forma ci- ocorre na maioria de radicais nominais que tomam clíticos pronominais curtos $(e-, e ́-)$. Porém, alguns radicais destas classes tomam o alomorfe zero (por exemplo, sérék 'pele dele'). Esse alomorfe zero é normal para radicais de verbos, adjetivos e auxiliares. A forma taa- ocorre em radicais das classes eé- e éè- que têm como primeira consoante uma dental. Se a consoante não for dental, ocorre a forma saa-.

Quando ocorre um pronome livre ao invés de um clítico pronominal, a pessoa se vê enfatizada, como no exemplo abaixo, em que panóóy indica 'nós (em contraste com outros)'.

$\begin{array}{llllll}\text { (2) óo } & \text { panóóy } & \text { sá } & \text { eé-na } & \text { s-aga } & \text { kí-nap } \\ \text { negative } & \text { nós } & \text { AUX.sujetivo } & \text { aquele-maneira } & \text { 3s-matar } & \begin{array}{l}\text { evidência- } \\ \text { indefinida }\end{array}\end{array}$

'Nós não matamos assim.'

\section{Clíticos pronominais em nomes, verbos, adjetivos e auxiliares}

As quatro classes de clíticos pronominais ilustradas acima com radicais nominais ocorrem com outras classes de palavra: verbos, adjetivos e auxiliares. As formas dos radicais intransitivos, ilustradas no quadro abaixo em parênteses, ocorrem somente em radicais de adjetivos complexos derivados por meio da partícula déè 'particípio'.

(3) Classe e-

\begin{tabular}{llllll}
\hline $\begin{array}{l}\text { Classe de pala- } \\
\text { vra }\end{array}$ & $\begin{array}{l}\text { Radical } \\
\text { nominal }\end{array}$ & $\begin{array}{l}\text { Radical de ver- } \\
\text { bo transitivo }\end{array}$ & $\begin{array}{l}\text { Radical de } \\
\text { verbo in- } \\
\text { transitivo }\end{array}$ & $\begin{array}{l}\text { Radical de } \\
\text { adjetivo }\end{array}$ & $\begin{array}{l}\text { Radical de } \\
\text { auxiliar }\end{array}$ \\
\hline Glossa & caminho & roubar & secar-se & aceso & assertativo \\
\hline $\mathbf{2 s}$ & ę-bé & ę-básanà & ę-gágąà & ę-gąày & ę-mága \\
\hline 3s & ci-pe & pásanà & (kágąà) & kąày & mága \\
\hline 3c & a-pe & a-pásanà & a-kágąà & a-kąày & --- \\
Pós-nominal & pé & pásanà & (kágąà) & kąày & mága \\
\hline Palavra livre & be & basanà & --- & --- & --- \\
\hline
\end{tabular}


(4) Classe é-

\begin{tabular}{llllll}
\hline $\begin{array}{l}\text { Classe de pala- } \\
\text { vra }\end{array}$ & $\begin{array}{l}\text { Radical } \\
\text { nominal }\end{array}$ & $\begin{array}{l}\text { Radical de ver- } \\
\text { bo transitivo }\end{array}$ & $\begin{array}{l}\text { Radical de } \\
\text { verbo intran- } \\
\text { sitivo }\end{array}$ & $\begin{array}{l}\text { Radical de } \\
\text { adjetivo }\end{array}$ & $\begin{array}{l}\text { Radical de } \\
\text { auxiliar }\end{array}$ \\
\hline Glossa & esposa & cobrir & dormir & velho & passado.ir \\
\hline 2s & é-zay & é-bogò & ę-gerè & é-gąày & ę-makáá \\
\hline 3s & ci-say & pogò & (kerè) & kąày & makáá \\
3c & a-say & a-pogò & a-kerè & a-kąày & --- \\
Pós-nominal & say & pogò & (kerè) & kąàyy & makáá \\
Palavra livre & --- & --- & gerè & --- & -- \\
\hline
\end{tabular}

(5) Classe eé-

\begin{tabular}{llllll}
\hline $\begin{array}{l}\text { Classe de pala- } \\
\text { vra }\end{array}$ & $\begin{array}{l}\text { Radical } \\
\text { nominal }\end{array}$ & $\begin{array}{l}\text { Radical de ver- } \\
\text { bo transitivo }\end{array}$ & $\begin{array}{l}\text { Radical de } \\
\text { verbo intran- } \\
\text { sitivo }\end{array}$ & $\begin{array}{l}\text { Radical de } \\
\text { adjetivo }\end{array}$ & $\begin{array}{l}\text { Radical de auxi- } \\
\text { liar }\end{array}$ \\
\hline Glossa & pilão & seguir.ação.PL & gritar & em pé & $\begin{array}{l}\text { passado. } \\
\text { definido-NOM }\end{array}$ \\
\hline $\mathbf{2 s}$ & eé-kabîi & ęé-bemáá & ęé-pęè & ęé-dóò & ęé-néè \\
\hline $3 s$ & saa-kabîi & saa- bemáá & (saa-pęè) & taa-dóò & ánéè \\
\hline 3c & aa-kabîi & aa-bemáá & aa-pęè & aa-dóò & aá-néè \\
\hline Pós-nominal & ákabîi & ábemáá & (ápęè) & ádóò & ánéè \\
\hline Palavra livre & akabîl & --- & --- & --- & --- \\
\hline
\end{tabular}

(6) Classe éè-

\begin{tabular}{llllll}
\hline $\begin{array}{l}\text { Classe de pala- } \\
\text { vra }\end{array}$ & $\begin{array}{l}\text { Radical } \\
\text { nominal }\end{array}$ & $\begin{array}{l}\text { Radical de } \\
\text { verbo transi- } \\
\text { tivo }\end{array}$ & $\begin{array}{l}\text { Radical de } \\
\text { verbo intran- } \\
\text { sitivo }\end{array}$ & $\begin{array}{l}\text { Radical de } \\
\text { adjetivo }\end{array}$ & $\begin{array}{l}\text { Radical de auxi- } \\
\text { liar }\end{array}$ \\
\hline Glossa & fígado & passar por & ir & alto & $\begin{array}{l}\text { (não há desta } \\
\text { classe) }\end{array}$ \\
\hline 2s & ęè-zaá & ęè-gą́á & ęe-gaà & ęè-tóò & \\
\hline 3s & cii-saá & saa-gąá & (kaà) & taa-tóò & aa-tóò \\
\hline 3c & aa-saá & aa-gáá & aa-kaà & atóò & \\
Pós-nominal & saá & agąá & (kaà) & --- & \\
\hline Palavra livre & --- & --- & -- & & - \\
\hline
\end{tabular}

Radicais nominais podem ser possuídos por sintagmas nominais, demonstrativos, pronomes livres ou clíticos pronominais; por exemplo, 'fígado' na tabela (6) acima. Outros radicais nominais, de acordo com a categoria à que pertencem, tomam o $\mathrm{SN}$, pronome, ou clítico pronominal precedente como argumento, não como possuidor.
(7) ę-bogò-p 'algo que cobre você
(8) ę-gakîy 'desejo de você'

O exemplo (7) é uma nominalização, na qual a pessoa marcada é o objeto do radical de verbo que foi nominalizado. No exemplo (8), o radical kakîy parece ser monomorfêmi$\mathrm{co}$, mas tem a pessoa marcada como argumento de objeto, não como possuidor. 
Em Gavião, radicais de adjetivos são sempre atributivos, nunca formas livres. Eles seguem o núcleo do sintagma nominal em que eles se encontram. O núcleo pode ser um nominal, um pronome livre ou um clítico pronominal. Um radical de adjetivo precedido por um clítico pronominal se distribui como qualquer sintagma nominal. As formas da terceira pessoa são genéricas, traduzindo-se com 'algo' ao invés de 'ele' ou 'eles'. No seguinte exemplo, o radical de adjetivo sot 'ruim', marcado com a terceira pessoa do plural, é um nominal predicativo.

$\begin{array}{lll}\text { (9) tá-sot } & \text { pa-máà aaná } & \text { 'Somos ruins agora.' } \\ 3 p \text {-ruim } & 1 \text { pi-COP agora }\end{array}$

Radicais de adjetivos podem também ser marcados com a primeira pessoa do plural para indicar humanos genéricos. No exemplo (10), o clítico pronominal, primeira pessoa plural inclusive, é o núcleo de um nominal predicativo, seguido por uma série de radicais adjetivais que o modificam.

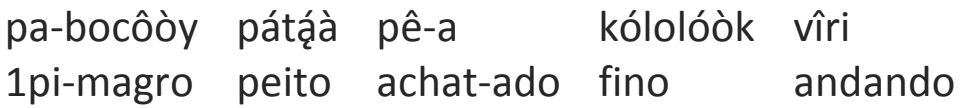

tá-sop máà tá-kalà-p koy-á

3p-pai COP 3p-querer-NMLZ em-marcador

'Os pais deles estavam andando magros com peitos caídos, com saudades deles.'

Uma oração Gavião pode conter múltiplos sintagmas verbais, com tempo, aspecto e tipo funcional da oração marcados no auxiliar, que segue imediatamente o sujeito. Ou seja, uma oração pode conter vários radicais de verbos. O exemplo seguinte tem como sujeito uma primeira pessoa plural inclusiva com quatro sintagmas verbais, dos quais três são transitivos (sublinhados). Dois dos objetos são zeros que indicam terceira pessoa.

$\begin{array}{llll}\text { palírí } & \text { pậ-a } & \text { má-'-éèy } & \text { kay } \\ \text { (3s)-compartilhar } & 1 \text { pi-AUX } & \text { outro-PL } & \text { envolver }\end{array}$

máà eé-na

(3s)-colocar aquela-maneira

'Nós a compartilhamos, colocando-a para os outros.' (chicha)

A marcação de pessoa nos radicais de verbos pode ser considerada ergativa, uma vez que o objeto é marcado no radical transitivo e o sujeito é marcado no radical intransitivo. Todavia, há uma diferença importante: a pessoa marcada no transitivo é o argumento do radical de verbo e pode ser substituída por um pronome livre, enquanto que a pessoa marcada no intransitivo somente marca concordância com o sujeito da cláusula imediata- 
mente dominante e não pode ser substituída por um pronome livre ou um sintagma nominal. No exemplo abaixo o sujeito é um clítico pronominal da primeira pessoa plural, $p a-$, e a pessoa está copiada no radical de verbo intransitivo, 'ficar'.

$\begin{array}{lll}\text { pâ-àt } & \text { pa-dá } & \text { kára-ále-á } \\ \text { 1pi-AUX.deixar } & 1 \text { pi-ficar } & \text { ainda-futuro-marcador } \\ \text { 'Vamos ficar ainda.' }\end{array}$

No exemplo abaixo, o sujeito é um sintagma nominal livre, 'ponta de pau', e a concordância de terceira pessoa está marcada no verbo 'sair'.

\begin{tabular}{|c|c|c|c|c|}
\hline$\frac{\text { îp }}{\text { pau }} \frac{\text { cipó }}{\text { ponto }}$ & $\begin{array}{l}\text { mé-ena } \\
\text { AUX.passado-assim }\end{array}$ & $\frac{\text { a-bíyą }}{3 c-s a i r}$ & $\begin{array}{l}\text { kîi } \\
\text { intensivo }\end{array}$ & iì \\
\hline
\end{tabular}

A forma canônica dos radicais de verbos intransitivos é um pouco diferente da forma das outras classes de radicais. Os radicais intransitivos das classes é- e éè- têm tom baixo e seus clíticos pronominais também têm tom baixo. Porém, quando estes radicais são nominalizados, o tom da nominalização tem o tom normal de um nome da classe. Por isto os clíticos pronominais baixos são considerados alomorfes e não uma classe diferente. Exemplo de radical de verbo da classe éè-:

$\begin{aligned} & \text { ęe-gaà } \\ & \text { 2s-ir }\end{aligned}$
2s-ir-NMLè-gaà-p vai

Um fenômeno interessante é a ausência de marcação de pessoa em uma categoria que chamamos verbos sem flexão (Autor 2002). Esta classe de palavra pode compor sozinha um sintagma verbal com as mesmas características que os demais sintagmas verbais em termos de movimento, negação, nominalização, etc. A classe inclui conceitos adverbiais; por exemplo, aaná 'hoje' em (9) ou eé-na 'daquela maneira' em (11) acima, bem como noções de atividades como gákoráá 'caçar' ou ibalà 'dançar'.

Os auxiliares na língua dos Gavião são imediatamente precedidos pelo argumento sujeito que pode ser um sintagma nominal, um pronome livre ou um clítico pronominal. Há uma exceção: o clítico pronominal que indica a correferência do sujeito de uma oração subordinada com o sujeito da oração principal correspondente. Ele marca concordância e não pode ser substituído por pronome. A correferência é marcada somente na terceira pessoa. No exemplo seguinte, o sujeito de uma subordinada nominalizada, aq́- 'terceira pessoa correferencial', é o mesmo que o sujeito da oração principal, tá- 'terceira pessoa plural'. As fronteiras da oração subordinada estão marcadas com colchetes. 
(15)
“eé-na
tá-máà
a-ma-ágąáá
aquela-maneira
3p-AUX.passado
3c-TRANS-amanhecer

[a-kapą́p

$$
\text { ma-'-ịi }
$$

aá-néè]

méne

3c-escuridão

TRANS-entrar

3c.AUX.passado-nominal

NMLZ.abstrata

ká-á"

ki-ìp

em-marcador evidência-lembrada

'Assim eles fizeram ficar de dia, quando eles colocaram escuridão (na vasílha)'.

\section{Correferência entre orações}

Nos exemplos disponíveis, um sujeito de terceira pessoa de uma oração subordinada que é correferencial com o sujeito da oração principal está sempre marcado com o clítico pronominal de terceira pessoa no auxiliar, como aá- no exemplo (15) acima. No caso de correferência marcada nos radicais de verbos transitivos, nomes ou adjetivos em uma oração subordinada, contudo, há uma ambiguidade formal. Pode haver correferência com o sujeito da oração subordinada ou com o da oração principal. No exemplo a seguir, o clítico pronominal aa- marca um objeto correferencial com o sujeito da oração subordinada, tá'eles', e não o sujeito da oração principal, 'ele', que está marcado como um zero no auxiliar.
ąá sáno píra má-ày
abiì
mága
este irmão com NMLZ.concreta-PL (=4)
matar.OBJ.PL (3s-)AUX

$\begin{array}{llll}\text { [aa-tíní } & \text { tá-sá-néè] } & \text { méne } & \text { ká } \\ \text { 3c-cuidar } & \text { 3p-AUX-NOM } & \text { NMLZ.abstrata } & \text { em }\end{array}$

'Ele (= o caçador) mata quatro (macacos) porque eles estão se cuidando.'

(Os macacos não fogem; eles tentam ajudar o macaco ferido, o que permite ao caçador matá-los.)

Já no próximo exemplo, o marcador de correferência no radical de verbo transitivo kay 'envolver' indica correferência com o sujeito da oração principal, tá- 'eles' ao invés do sujeito da oração subordinada, alóp 'ele'.
eé bó tá-máà
alóp ka
va
aá-nít
aí foco 3p-AUX.passado
ele cheiro ingerir
esta-quantidade.DIMIN 
alóp ka-néè a-kay mát ká

ele (AUX)-ir-NOM 3c-envolver NMLZ.concreta em

'Aí eles sentiram o cheiro dele quando ele foi até eles.'

\section{Marcação de pessoa em palavras complexas}

A sintaxe Gavião contém um sistema elaborado de palavras sintáticas, ou seja, construções compostas de mais de uma palavra simples que se distribuem dentro do sintagma como uma palavra simples. É interessante notar que os radicais de palavras sintáticas têm a mesma marcação de pessoa que os radicais simples. No exemplo que segue, o radical vít 'comida' está incorporado em um radical de verbo intransitivo sintático (em colchetes). 0 clítico pronominal, pa- '1pi' copia a pessoa do sujeito da cláusula, $p a-$ '1pi', marcado no auxiliar.

$$
\begin{array}{llll}
\text { pa-[vít } & \text { viì] } & \text { té } & \text { pa-zá } \\
\text { 1pi-comida } & \text { cozinhar.se } & \text { não.asserção } & 1 \text { pi-AUX.não.asserção }
\end{array}
$$

eé pí kay

aquele de (3s)-envolver

'Daí cozinhamos nossa comida com ela?' (cerâmica)

Em tais casos, a classe do clítico pronominal é a classe do primeiro radical do radical complexo, neste exemplo vít 'comida'. A classe do prefixo é uma propriedade do radical, não do primeiro morfema, como ilustrado no exemplo abaixo.

$\begin{array}{ll}\text { (19) ę-jiit 'seu sangue' } & \text { ę-jír-alà } \\ \text { 2s-sangue } & \text { 2s-sangue-cair }\end{array}$

\section{Referências}

MOORE, D. Cláusulas Relativas de Gavião de Rondônia. Boletim do Museu Paraense Emilio Goeldi. Zoologia, Belém, v. 1, p. 135-143, 2006.

MOORE, D. Verbos sem Flexão. In: A. S. A. C. Cabral; A. D. Rodrigues. (Orgs.). Língua Indígenas Brasileiras: Fonologia, Gramática e História; Atas do Primeiro Encontro Internacional do Grupo de Trabalho sobre Línguas Indígenas da ANPOLL. Belém: Editora Universitária UFPA, 2002, v. Tomo I, p. 139-150.

MOORE, D. Syntax of the Language of the Gavião Indians of Rondônia (Brazil). Tese (Doutorado em antropologia) - City University of New York, Nova York, 1984. 